\title{
Application of Plackett Burman Design for Antioxidant Extraction from Actinodaphne sesquipedalis leaves
}

\author{
Siti Fatihah Balqis Binti Jamaludin, Siti Salwa Binti Abd Gani,Uswatun Hasanah Binti Zaidan, \\ Paiman Bin Bawon
}

\begin{abstract}
Actinodaphne sesquipedalis Hook. F. Var. Glabra (Kochummen), also known as "Medang payung" by the Malay people, belongs to the Lauraceae family. In this study, a Plackett-Burman design was used to evaluate the significant extraction parameters in achieving maximum DPPH radical scavenging activity from ethanol leaves extract of $A$. sesquipedalis. Microwave-assisted extraction technique was employed using aqueous ethanol. The independent parameters were microwave power level $(30-60 \mathrm{~W})$, feed-to-solvent ratio $(1: 30 \mathrm{~g} / \mathrm{ml})$, irradiation time (30-90 s) and ethanol concentration (20-80\%). Amongst the examined parameters, ethanol concentration, microwave power level, and irradiation/extraction time were significant, whereas, feed-to-solvent ratio was insignificant. Therefore, antioxidants from the ethanolic extraction leaves of A. sesquipedalis using microwave technique are significantly affected by ethanol concentration, irradiation time and microwave power.
\end{abstract}

Index Terms: Actinodaphne sesquipedalis, DPPH radical scavenging activity, microwave, Plackett-Burman design.

\section{INTRODUCTION}

Antioxidants play an important role as a health protecting factors [1]. According to Chanda and Nagani (2010), antioxidants may describe as compounds that inhibit or delay the oxidation of other molecules by inhibiting the initiation or propagation of oxidizing chain reaction [2]. Within normal human body's functions, free radicals are form from by-products of specific oxidation reactions which eliminates pathogens and infected cells. However surplus of these highly reactive species can induced chain reactions that damage cells and if uncontrollable will cause many kinds of diseases [3]. Antioxidants generally occur naturally in plants, fruits and whole grains and previous studies affirmed that, highly present of antioxidant compounds such as polyphenols, carotenoids, tocopherols, tocotrienols, glutathione and ascorbic acid, as well as enzymes with antioxidant activity [4]. Antioxidants significantly become

Revised Manuscript Received on September 22, 2019.

Siti Fatihah Balqis Binti Jamaludin, Halal Products Research Institute, University Putra Malaysia, Serdang, Malaysia.

Siti Salwa Binti Abd Gani, Department of Agriculture Technology, Faculty of Agriculture, University Putra Malaysia, Serdang, Malaysia.

Uswatun Hasanah Binti Zaidin, Department of Biochemistry, Faculty of Biotechnology and Biomolecular Sciences, University Putra Malaysia, Serdang, Malaysia.

Paiman Bin Bawon, Department of Forest Production, Faculty of Forestry, University Putra Malaysia, Serdang, Malaysia. great to overcome the aging problem and at the same time to reduce getting a serious illness. Therefore, the aim of this study has been focused on exploring natural antioxidants from plant sources.

Actinodaphne sesquipedalis Hook. F. Var. Glabra (Kochummen), also known as "Medang payung" by the Malay people, belongs to the Lauraceae family [5]. Previously, the genus Actinodaphne was also used as a traditional Chinese medicine for the treatment of stomachache [6]. Actinodaphne plants are rich in diverse biological active alkaloids, which have phytopharmaceutical properties [7]-[10]. In this work, the determination of important variables is studied for the leaves extraction of A.sesquipedalis in obtaining higher antioxidant capacity. However, extraction of antioxidant from the plant matrix has usually been achieved through either conventional or unconventional method using different solvents.

Extraction is very important in the recovery of phytochemicals from plant matrix. For instance, microwave-assisted extraction is more effective in the quality of antioxidant capacity from plant matrix in a shorter time as compared with a conventional method like soxhlet, maceration and others [11], [12]. Nevertheless, this method is being affected by different extraction parameters, irradiation time, temperature, microwave power level, feed-to-solvent ratio, and solvent concentration [13]. In order to minimize cost, the contributing extraction parameters need to be evaluated. Although, the one-factor-at-a-time experiment was the most used method but the approach is expensive, time-consuming and may give in inaccurate results since it does not consider interactive parameters [14]. To contain these shortcomings, a factorial design is being used as a statistical screening process. This approach is useful in evaluating main as well as interactive effects during the extraction with minimal experimental runs. Thus, the aim of this study is to screen the independent factors, namely microwave power level $(30-60 \mathrm{~W})$, feed-to-solvent ratio $(1: 15-1: 30 \mathrm{~g} / \mathrm{ml})$, irradiation time $(30-90 \mathrm{~s})$ and ethanol concentration (20-80\%) for the antioxidant activity from $\mathrm{A}$ sesquipedalis leaves using Plackett-Burman factorial design.

The Plackett-Burman experimental design, a fractional factorial design, was used in this work to demonstrate the relative importance of extraction parameter and response.

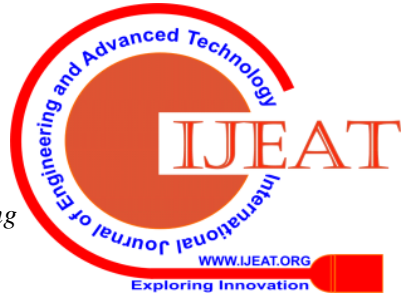




\section{MATERIALS AND METHOD}

\section{A. Reagent and Plant Material}

Fresh leaves of $A$. sesquipedalis were harvested from Ayer Hitam Forest Reserve in Malaysia. The leaves collected will be washed with tap water and chopped coarsely and left to dry overnight in the oven temperature not more than $40^{\circ} \mathrm{C}$ for 24 hours. The air-dried leaves will be ground using a mechanical blender. They were then gently pulverized into powder form and stored in an air tight plastic container. DPPH (1,10-diphenyl-2-20-picrylhydrazyl) and ethanol were purchased from Sigma Aldrich. Only the analytical grade of chemicals was used throughout the experiment.

\section{B. Extraction Process}

The extraction process was carried out based on a factorial design using two coded levels of each extraction variable (low and high levels) as illustrated in Table I. The variables were irradiation time $(30-90 \mathrm{~s})$, microwave power level $(30-60 \mathrm{~W})$, feed-to-solvent ratio $(1: 30 \mathrm{~g} / \mathrm{ml})$, and ethanol concentration (20-80\%). $10 \mathrm{~g}$ of powdered A. sesquipedalis leaves was extracted using aqueous ethanol in an enclosed microwave extractor. The variables were set based on the Plackett-Burman factorial experimental design matrix (Table III). After extraction, the extract was filtered and concentrated to dryness using a rotary evaporator at $750 \mathrm{C}$ The extract was then refrigerated at $-20 \mathrm{oC}$ until further analysis.

\section{DPPH Radical Scavenging Activity}

The radical scavenging activity of each sample was carried out followed a method described by Blois, 1958 [15] with modification. Briefly, $10 \mathrm{mg}$ of dried extract was weighed and dissolved in $10 \mathrm{~mL}$ ethanol $(1 \mathrm{mg} / \mathrm{mL}) .10 \mathrm{mg}$ of 1-diphenyl-2-picrylhydrazyl (DPPH) radical was dissolved in ethanol and made up to $100 \mathrm{~mL}$ in a volumetric flask $(0.1$ $\mathrm{mM})$. Then $50 \mu \mathrm{L}$ of the extracts sample was mixed with 150 $\mu \mathrm{L}$ ethanolic solution of DPPH in 96-well plate microliter plate. The solution mixture was incubated in the dark at room temperature and the absorbance changes at $515 \mathrm{~nm}$ was measured 30 min later using a UV-VIS microplate reader. The sample extract without DPPH was used as blank test. All the analysis was conducted in triplicate, and the concentration required for $50 \%$ reduction (50\% inhibition concentration, IC50) of DPPH radical solution was determined graphically. The DPPH scavenging activities of the extracts was calculated using the following equation: DPPH scavenging activity $(\%)=$

$$
((\mathrm{A} 0-\mathrm{A} 1)) / \mathrm{A} 0 \times 100 \text {, }
$$

Where $\mathrm{A} 0$ is the absorbance of the blank sample and A1 is the absorbance of the sample.

\section{Experimental design}

In the evaluation of four variables at two coded levels, a Plackett-Burman factorial design with 12 experimental trials was carried out in a randomized trend. The range and the levels of the experimental variables used in the coded form are presented in Table I. For each variable, a high (5) and low
(1) level was tested. The experimental runs and the analyses were carried out in triplicate. The resulting values and statistical analysis were processed using Minitab 14 statistical software.

The Plackett-Burman design has permitted the response to be modeled by the first-order polynomial, which can be expressed as the equation:

$$
\mathrm{Y}=\mathrm{b} 0+\mathrm{b} 1 \mathrm{X} 1+\mathrm{b} 2 \mathrm{X} 2+\mathrm{b} 3 \mathrm{X} 3+\mathrm{b} 4 \mathrm{X} 4
$$

Where $\mathrm{Y}$ is the response function. $\mathrm{X} 1, \mathrm{X} 2, \mathrm{X} 3$ and $\mathrm{X} 4$ are the independent variables. $\mathrm{b} 0$ is the average theoretical value of the response. b1, b2, b3, and b4 are the factor effects of X1, $\mathrm{X} 2, \mathrm{X} 3$, and $\mathrm{X} 4$ respectively.

Table- I: Extraction parameters and their level.

\begin{tabular}{lccc}
\hline & Variables & \multicolumn{2}{c}{ Range } \\
\cline { 3 - 4 } & & 1 (low level) & 5 (high level) \\
\hline A & IrradiationTime, s & 20 & 80 \\
B & Power, watt & 30 & 60 \\
C & Solvent concentration,\% & 30 & 90 \\
D & Solid to Solvent Ratio & $15 \mathrm{ml} / \mathrm{g}$ & $30 \mathrm{ml} / \mathrm{g}$ \\
\hline
\end{tabular}

\section{RESULTS AND DISCUSSION}

\section{A. Fitting the Process Variables.}

The experimental data for the response DPPH radical scavenging activity of red pitaya seed extracts are displayed in Table II. The result obtained showed that the DPPH radical scavenging activity of $\mathrm{A}$. sesquipedalis leaves extract ranged from $82.05-87.34 \%$. The influence of some extraction variables sometimes can be more significant than others. The use of an insignificant variable in the extraction process may give incorrect or inappropriate results [15]. Thus, factor screening is inevitable for the extraction process. The identification of the extraction parameters that are likely to be effective were done. In general, it can be observed from the p-values $(p<0.005)$ in Table III that irradiation time, microwave power level and ethanol concentration were significant variables response to the antioxidant activity. Ethanol concentration has the lowest p-values among other factors. This shows that ethanol concentration give the highest contribution response to the antioxidant activity. In addition, our results are supported by normal probability plots values to find the most important effects and interactions. In normal probability plots, the minor effects fall on a straight line, whereas important effects would be located off the line. The normal probability plots for the factorial design are shown in Fig. 1. It can be seen that ethanol concentration, microwave power level and irradiation time are the important factors affecting the determination of antioxidant capacity while other extraction factor which is solid to solvent ratio remained unimportant.

\section{B. Influence of Extraction Parameters on Antioxidant Capacity}

Among all of the factors only solid to solvent ratio was not significant, while ethanol concentration, irradiation time and were significant in obtaining higher antioxidant capacity. The effect of ethanol 
concentration was the major contributor for antioxidant activity which is DPPH radical scavenging assay.

Table- II: The experimental design in coded form for the determination of significant variables using

Plackett-Burman factorial design and response.

\begin{tabular}{llllll}
\hline \multirow{2}{*}{ Order } & \multicolumn{3}{c}{ Coded value } & Response \\
\cline { 2 - 6 } & A & B & C & D & DPPH, \% \\
\hline 1 & 1 & 5 & 5 & 1 & 83.04 \\
2 & 1 & 1 & 1 & 5 & 86.73 \\
3 & 1 & 1 & 5 & 5 & 83.26 \\
4 & 5 & 1 & 5 & 5 & 85.37 \\
5 & 1 & 5 & 5 & 5 & 82.05 \\
6 & 5 & 1 & 1 & 1 & 87.33 \\
7 & 1 & 1 & 1 & 1 & 87.34 \\
8 & 1 & 5 & 1 & 1 & 86.13 \\
9 & 5 & 5 & 5 & 1 & 84.46 \\
10 & 5 & 5 & 1 & 5 & 87.34 \\
11 & 5 & 5 & 1 & 5 & 85.92 \\
12 & 5 & 1 & 5 & 1 & 87.00 \\
\hline
\end{tabular}

A greater slope indicates a greater effect of a given factor on the antioxidant capacity. Thus, the proportion of ethanol concentration in the extraction medium had a significant influence on the antioxidant properties of leaves extract of A.

sesquipedalis. Antioxidant activity decreased with increasing ethanol concentrations. Antioxidant capacity was sensitive to solvent polarity, and a single ethanol concentration recovered all individual phenolic and antioxidant plant compounds. Previous study showed that extracts from Clerodendrum cyrtophyllum Turcz leaves obtained at low ethanol concentrations $(40 \%)$ had a greater scavenging capacity for both DPPH and ABTS radicals. Excessive quantities of solvent can compromise the extraction of phenolic compounds and impair their antioxidant capacity, $40 \%$ ethanol was used for subsequent RSM to optimize extraction conditions [16]. Based on Fig. 2, during low (20\%) ethanol concentration, higher antioxidant Antioxidant activity decreased to $84.1967 \%$, when ethanol concentration increased to $80 \%$. In this study, higher irradiation times gives higher antioxidant activity. Extraction time was selected based on heating efficiency with microwave. Therefore from Fig. 2, the lower microwave power level gives higher antioxidant capacity. This phenomenon probably due to chemical and thermal degradation of some phenolic compounds accounting for decreased antioxidant activity which were previously mobilized at low temperature [17]. It has been reported that greater absorbance of microwave energy by polar molecules, such as polyphenolic compounds, can result in greater solution temperature, which causes the decomposition of the extracted components. This can be a reason for the decrease in the antioxidant activity of the extracts from this study at higher power levels of the microwave.

Table- III: The p-values of response $\mathrm{P}$-values of response activity was noticed which is the mean value is $86.7963 \%$.

\begin{tabular}{ll}
\hline Irradiation time, s & 0.015 \\
Microwave power level, watt & 0.022 \\
Ethanol concentration, \% & 0.001 \\
Feed to solvent ration, g/ml & 0.137
\end{tabular}

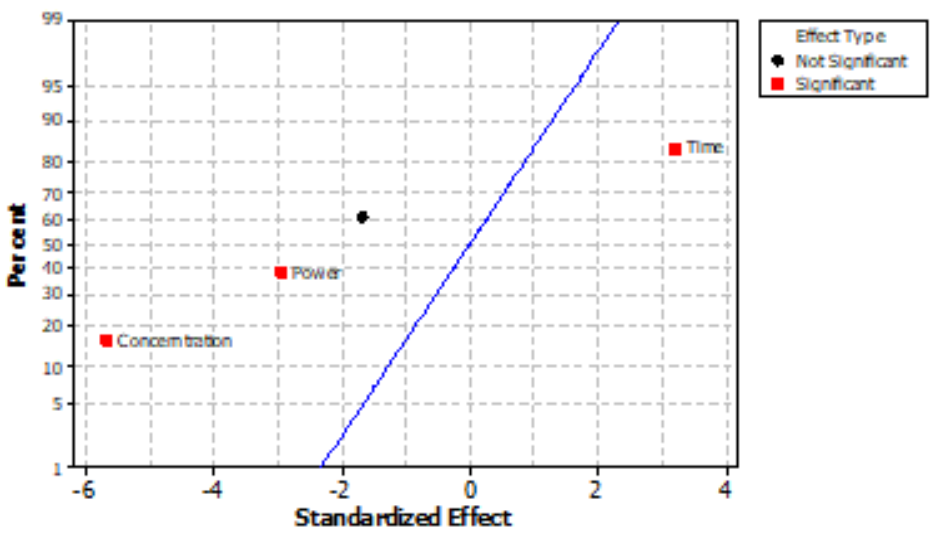

Fig. 1. Normal Probability Plot

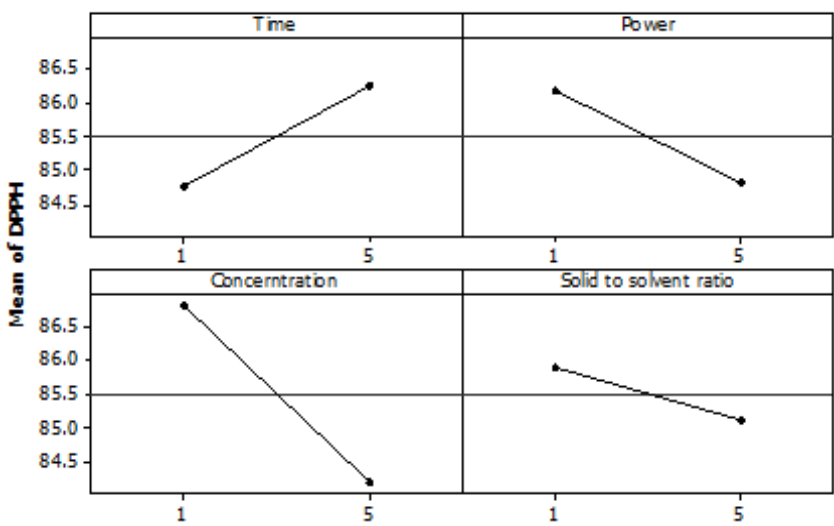

Fig. 2. Main effect plot of four independent variables; Irradiation time (s), Microwave power level (watt), Ethanol concentration $(\%)$ and Solid to solvent ratio $(\mathrm{g} / \mathrm{ml})$

\section{CONCLUSION}

The Plackett-Burman factorial design screening was used to evaluate the significance of microwave-assisted extraction parameters, which include irradiation time, microwave power level, feed-to-solvent ratio, and ethanol concentration in obtaining an antioxidant activity (DPPH) from leaves extract of A. sesquipedalis. The obtained results showed that ethanol concentration, microwave power level and irradiation time, were significant $(\mathrm{p}<0.05)$ in attaining higher antioxidant activity. Using these significant factors, further experiments are warranted to determine the optimum extraction conditions using response surface methodology and to determine the bioactive constituents.

\section{REFERENCES}

1. Z. Sadeghi, J. Valizadeh, O. A. Shermeh, and M. Akaberi, "Antioxidant activity and total phenolic content of Boerhavia elegans (choisy) grown in Baluchestan, Iran," Avicenna J Phytomed, vol. 5, no. 1, 2015 , pp. $1-9,201$ 
2. S. V. Chanda, and K. V. Nagani, "Antioxidant Capacity of Manilkara zapato Leaves Extracts Evaluated by Four in vitro Methods," Nat and Sci., vol. 8, no.10, 2010, pp. 797-802.

3. K. Boonmee, S. Chuntranuluck, V. Punsuvon, and P. Silayoi, "Optimization of biodiesel production from Jatropha (Jatropha c urcas L.), using surface response methodology," K. J. Nat. Sci., vol. 44, no. 2, 2010, pp. 290-299.

4. P. C. H. Hollman, "Evidence for health benefits of plant phenols: Local or systemic effects?," J. Sci. Food Agric., vol. 81, no. 9, 2001, pp. 842-852.

5. H. Omar, N. Nordin, P. Hassandarvish, M. Hajrezaie, A. H. Azizan, and M. Fadaeinasab, N. A. Majid, M. A. Abdulla, N. M. Hashim, and H. M. Ali, "Methanol leaf extract of Actinodaphne sesquipedalis (Lauraceae) enhances gastric defense against ethanol-induced ulcer in rats," Drug Des. Dev. Ther., vol. 11, 2017, pp. 1353-1365.

6. C. M. Kim, M. K. Shin, D. K. Ahn, and K. S. Lee, "Chinese medicine dictionary," Jungdam Co., vol. 6, 1998, pp 3398.

7. S. Z. Moghadamtousi, E. Rouhollahi, H. Karimian, M. Fadaeinasab, M. A Abdulla, and H. A. Kadir, "Gastroprotective activity of Annona muricate leaves against ethanol-induced gastric injury in rats via Hsp70/Bax involvement," Drug Des Devel Ther., vol. 28, no. 8, 2014, pp. 2099-2110.

8. N. Wiseman, and F. Ye, A Practical Dictionary of Chinese Medicine, 2nd ed, Brookline, MA: Paradigm Publications; 1998.

9. S. Bhakuni, N. C. Gupta, S. Satish, S. C. Sharma, Y. N. Shukla, and J. S. Tandon, "Chemical constituents of Actinodaphne augustifolia, Croton sparsiflorus, Duabanga sonneratiodes, Glycosmis mauritiana, Hedyotis auricularia, Lyonia ovalifolia, Micromelum pubescens, Pyrus pashia and Rhododendron niveum, Phytochemistry, vol. 10, no. 9, 1971, pp. 2247-2249.

10. S. T. Lu, S. J. Wang, and F. S. Lin, "Studies on the alkaloids of Formosan lauraceousplants. XIV. Alkaloids of Actinodaphne acutivena (hayata) Nakai and Litsea hayatae Kanehira," Yakugaku Zasshi.. Japanese [with English abstract], vol. 89, no. 9, 1969, pp. 1313-1316.

11. C. H. Chan, R. Yusoff, G. C. Ngoh, and F. W. L. Kung, "Microwave-assisted extractions of active ingredients from plants," $J$. Chromatogr. A., vol. 1218, no. 37, 2011, pp. 6213-6225.

12. M. Desai, J. Parikh, and P. A. Parikh, "Extraction of natural products using microwaves as a heat source," Sep. Purif. Rev., vol. 39, no. 1-2, 2010, pp. $1-32$.

13. P. Raut, D. Bhosle, A. Janghel, S. Deo, C. Verma, S. S. Kumar, M Agrawal, N. Amit, N. M. Sharma, M. T. Giri, D. K. Tripathi, A. Ajaz, and A. Alexander, "Emergingmicrowave assisted extraction (MAE) techniques as an innovative green technologies for the effective extraction of the active phytopharmaceuticals," Res. J. Pharm. Technol., vol. 8, no. 5, 2015, pp. 800-810.

14. D. D. Frey, F. Engelhardt, and E. M. Greitzer, "A role for one-factor-at-a-timecexperimentation in parameter design," Res. Eng. Des. vol. 14 , no. 5, 2015, pp. 65-74.

15. M. S. Blois, "Antioxidant determinations by the use of a stable free radical," Nature, vol. 29, 1958, pp. 1199-1200.

16. J. Zhou, X. Zheng, Q. Yang, Z. Liang, D. Li, and X. Yang, "Optimization of Ultrasonic-Assisted Extraction and Radical-Scavenging Capacity of Phenols and Flavonoids from Clerodendrum cyrtophyllumTurcz Leaves," PLoS ONE, vol. 8, no. 7, 2013, pp. e68392.

17. M. Silva, H. Rogez, and Y. Larondelle, "Optimization of extraction of phenolics from Inga edulisleaves using response surface methodology," Sep. Purif. Technol., vol. 55, no. 3, 2007, pp. 381-387.

\section{Authors Profile}

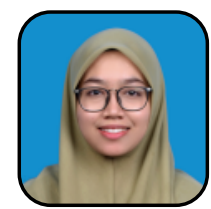

Siti Fatihah Balqis Binti Jamaludin, Master of Science, 2016, Halal Product Development, Halal Products Research Institute, University Putra Malaysia, 43400 Serdang, Selangor, Malaysia..

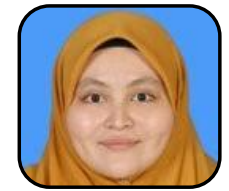

Siti Salwa Binti Abd Gani, Doctor of Philosophy, 2010,Agricluture Product Development, Oleochemistry and Formulation Science Halal Product Development, University Putra Malaysia, 43400 Serdang, Selangor, Malaysia.

Uswatun Hasanah Binti Zaidin, Doctor of Philosophy Food Biochemistry Sciences, University Putra Malaysia, Serdang, Malaysia.

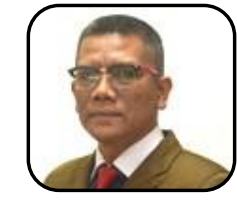

Paiman Bin Bawon, Doctor of Philosophy, Wood Science University Putra Malaysia, Serdang, Malaysia.

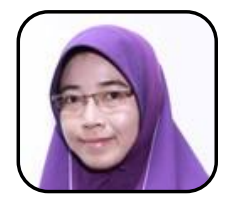

Retrieval Number: F10080986S319/2019@BEIESP 